\title{
Chronic inflammatory demyelinating polyneuropathy with hypoglossal nerve involvement and inverted Beevor's sign: case report
}

\author{
Huajian Zhao ${ }^{1,2}$, Yiming Zheng ${ }^{1 *}$, Lingchao Meng ${ }^{1}$, Meng Yu', Wei Zhang ${ }^{1}$, He Lv', Zhaoxia Wang ${ }^{1}$,
} Hongjun $\mathrm{HaO}^{1}$ and Yun Yuan ${ }^{*}$

\begin{abstract}
Background: Cranial nerve involvement is not commonly encountered in chronic inflammatory demyelinating polyradiculoneuropathy (CIDP); this is especially true for involvement of the hypoglossal nerve. Neither Beevor's sign nor its inverted form has previously been described in CIDP.

Case presentation: A 28-year-old man presented with distal-predominant limb weakness and numbness at the age of 18. A diagnosis of CIDP was made, which was confirmed by electrodiagnostic evidence of demyelination. He responded well to intravenous immunoglobulin and glucocorticoid treatment and achieved remission for 5 years. However, the same symptoms relapsed at the age of 28 and lasted for 10 months. On examination, in addition to limb sensory impairment and muscle weakness, mild bilateral facial paresis, tongue atrophy and fasciculations, and inverted Beevor's sign were also observed. A brief literature review of cranial nerve involvements in CIDP and Beevor's sign or its inverted form were also performed.
\end{abstract}

Conclusions: Cranial nerves may be affected in patients with CIDP. Facial palsy is most frequently present, while hypoglossal nerve involvement is rare. Inverted Beevor's sign can appear in CIDP patients.

Keywords: Chronic inflammatory demyelinating polyneuropathy, Hypoglossal neuropathy, Facial neuropathy, Beevor's sign

\section{Background}

Chronic inflammatory demyelinating polyneuropathy (CIDP) is a rare, acquired, immune-mediated neuropathy that affects the peripheral nerves and nerve roots. It is characterized by a relapsing-remitting or progressive course and evidence of demyelination [1]. Typical CIDP is a symmetric sensorimotor polyneuropathy that causes both proximal and distal limb weakness, sensory

*Correspondence: 804067836@qq.com; yuanyun2002@sohu.com

${ }^{1}$ Neurology Department, Peking University First Hospital, No.8 Xishiku

Street, Beijing 100034, China

Full list of author information is available at the end of the article impairment, and areflexia. Cranial nerve involvement is not commonly encountered; this is especially true for the involvement of the hypoglossal nerve [2,3]. Beevor's sign is an upward umbilicus deviation when a supine patient tries to sit up, and indicates predominant weakness of the lower rectus abdominis muscle. It can also be present in an "inverted" form [4]. Beevor's sign or its inverted form is mainly present in myopathies, such as facioscapulohumeral muscular dystrophy, but to our knowledge, it has never been described in CIDP [5]. In the present report, we describe uncommon findings in a patient with CIDP, cranial nerve involvement, and inverted Beevor's 
sign, and report the results of a brief literature review. Literature search with relevant keywords (including cranial nerve and CIDP, or Beevor's sign) was conducted in the PubMed databases up to October 2020.

\section{Case presentation}

A 28-year-old man presented with a relapsing-remitting course of distal-predominant limb weakness and numbness for 10 years. Ten years earlier, he had gradually progressive weakness and numbness in the distal limbs. He was unable to write, button his clothes, or open jars, but had no difficulty in climbing stairs or rising from a seated position. He was treated with intravenous dexamethasone and subsequent oral prednisolone for 1 month in another hospital, although the specific dosage was unknown. His symptoms disappeared after treatment. However, 7 years ago, the same symptoms relapsed and were gradually progressive. He presented at our hospital because of persistence of the aforementioned symptoms. He was treated with intravenous immunoglobulin at $0.4 \mathrm{~g} / \mathrm{kg} /$ day for 5 days, and intravenous methylprednisolone at $500 \mathrm{mg}$ per day for 3 days, followed by $240 \mathrm{mg}$ per day for 1 day and $120 \mathrm{mg}$ per day for 1 day. Subsequently, he received $55 \mathrm{mg}$ of oral prednisolone for 1 month, after which it was gradually tapered off. He also took cyclosporine at $50 \mathrm{mg}$ twice per day. In addition, he was subjected to another two 5-day courses of intravenous immunoglobulin, at 6 years ago and 5 years ago. $\mathrm{He}$ began to gradually recover after treatment and achieved remission, and he stopped all treatment 5 years ago. However, his symptoms relapsed 10 months ago, with gradually progressive asymmetrical weakness and numbness in his distal arms and legs. His left upper limb was most affected. He had no known comorbid conditions and no relatives with a similar condition.

On neurological examination, the patient had mild bilateral facial paresis, asymmetric atrophy of the tongue muscle, and tongue fasciculations (Fig. 1, A and B, and Video 1). No dysarthria or dysphagia was observed. Pinprick and vibration sensations under the wrists and ankles were significantly decreased, while sensation of the trunk was normal. No marked atrophy of the limb muscles was observed. The arms and legs were asymmetrically weak, with a Medical Research Council scale strength of $1-4$, and predominant involvement of the upper distal extremities (Supplementary Materials Table 1). Tendon reflexes including bilateral biceps, triceps, brachioradialis, knee and ankle tendon reflexes were absent, and the Babinski sign was negative. An inverted Beevor's sign was also observed, characterized by a downward movement of the patient's umbilicus while attempting to stand from a recumbent position (Fig. 1, C and D, and Video 2).
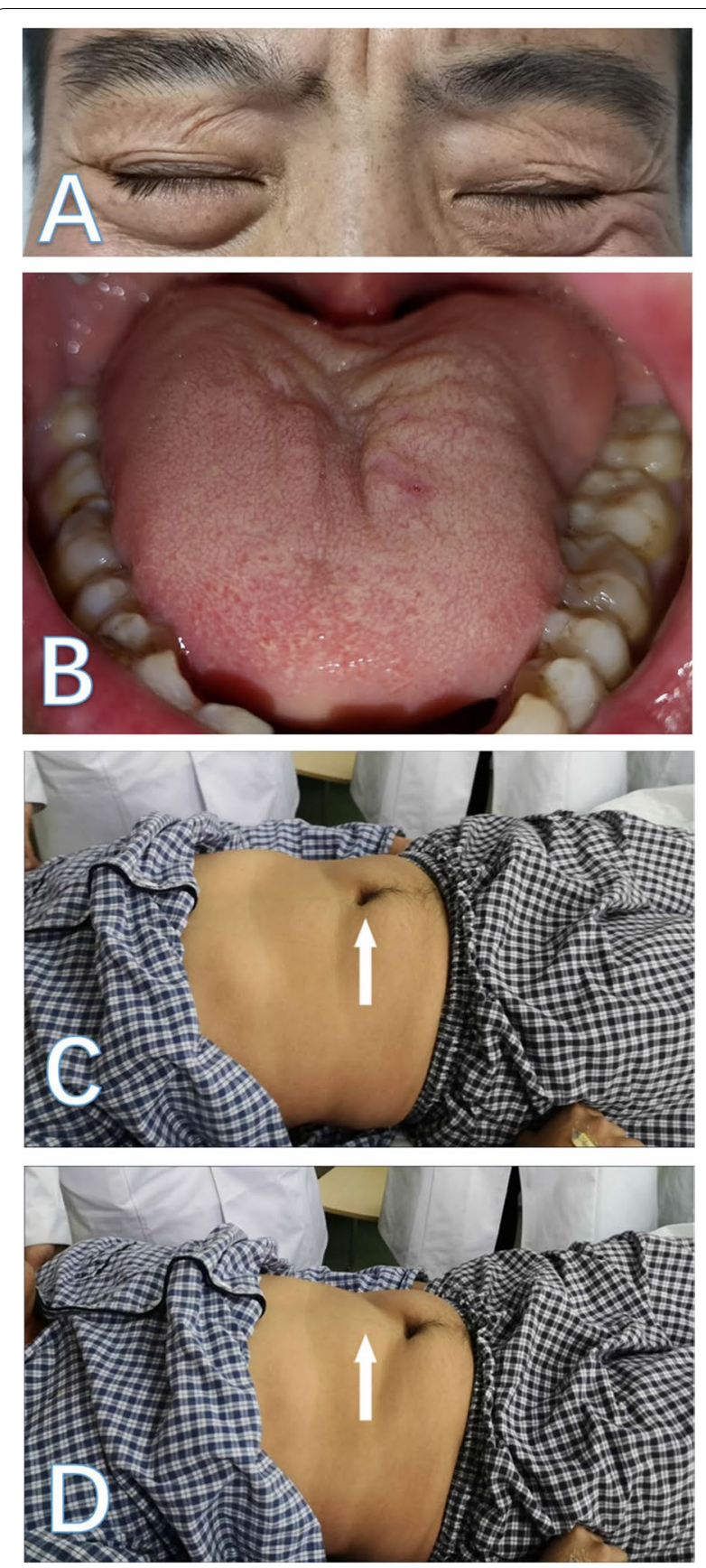

Fig. 1 Cranial nerve involvement and inverted Beevor's sign in the patient. The patient was unable to bury the eyelashes during forced eyelid closure, indicating facial muscle weakness $(\mathbf{A})$. His tongue showed marked asymmetrical atrophy (B). A downward movement of his umbilicus while attempting to stand from a recumbent position ( $\mathbf{C}$ and $\mathbf{D})$

Laboratory evaluations, including a complete blood count, erythrocyte sedimentation rate, C-reactive protein, antinuclear antibodies, anti-neutrophil cytoplasmic antibody, fasting serum glucose, thyroid function studies, 
serum and urine protein electrophoresis and immunofixation, and angiotensin-converting enzyme, were all unremarkable. Anti-ganglioside antibodies, myelin-associated glycoprotein, neurofascin 155 and 186, and contactin 1 were all negative. In addition, cerebrospinal fluid analysis revealed a normal protein content, cell count, and glucose level. Electrodiagnostic testing revealed severe, diffuse, asymmetric sensorimotor polyneuropathy that fulfilled the criteria for primary demyelination in CIDP. This included prolonged distal motor latencies, delay and disappearance of $F$ waves, and conduction block in the radial and ulnar nerves (Table 1). The nerve ultrasonography showed segmental hypertrophy in the bilateral median and ulnar nerves (Supplementary Materials Table 2). Magnetic resonance imaging of the lumbosacral plexus revealed that the L5 and S1 spinal roots were mildly enlarged (Supplementary Materials Fig. 1). A biopsy of the left sural nerve was almost normal and vasculitis was excluded.

The patient was diagnosed with CIDP, and was again treated with intravenous immunoglobulin at $0.4 \mathrm{~g} / \mathrm{kg} /$ day for 5 days, intravenous methylprednisolone at $500 \mathrm{mg}$ per day for 3 days, and then oral prednisolone at $60 \mathrm{mg} /$ day for 1 month before it was gradually tapered off. The patient was followed up by telephone. After 3 months of treatment, his numbness was completely relieved, his limb strength was recovered about $70 \%$, he had no difficulty in daily life, and he returned to work.

\section{Discussion and conclusions}

In the current report, we present a case with chronically recurrent limb weakness and sensory dysfunction as well as cranial nerve involvement. The patient's tendon reflexes were absent in all extremities. His nerve conduction velocity study results met the electrodiagnostic criteria for CIDP, and he responded well to immunomodulatory treatment. Other causes were excluded by extensive clinical and laboratory evaluations. According to the European Federation of Neurological Societies and the Peripheral Nerve Society criteria, the diagnosis of the present patient was definite CIDP [6]. Furthermore, the upper limb predominance and asymmetric involvement in this patient indicated a diagnosis of an atypical variant of CIDP: multifocal acquired demyelinating sensory and

Table 1 Nerve conduction velocity study of the patient

\begin{tabular}{|c|c|c|c|c|c|c|c|}
\hline Nerves & Left & & & Right & & & \\
\hline Motor nerve & $\operatorname{MCV}(\mathrm{m} / \mathrm{s})$ & CMAP $(\mathrm{mV})$ & Distal latency (ms) & $\operatorname{MCV}(\mathrm{m} / \mathrm{s})$ & CMAP $(\mathrm{mV})$ & & Distal latency (ms) \\
\hline Median nerve & & & & & & & \\
\hline Wrist-APB & no response & & & no response & & & \\
\hline Ulnar nerve & & & & & & & \\
\hline Wrist-ADM & & 3.7 & 2.6 & & 7.8 & & 2.6 \\
\hline Below elbow-Wrist & 42.9 & 1.2 & & 50.4 & 5.9 & & \\
\hline Above elbow-Below elbow & no response & & & no response & & & \\
\hline Radial nerve & & & & & & & \\
\hline Elbow-EDC & & 5.0 & 3.1 & & 8.9 & & 2.8 \\
\hline Axilla-Elbow & 58.8 & 1.6 & & 64.5 & 3.6 & & \\
\hline Peroneal nerve & & & & & & & \\
\hline Ankle-EDB & no response & & & no response & & & \\
\hline CF-Down-2 cm-Tibialis anterior muscle & & 6.2 & 4.1 & & 5.3 & & 2.8 \\
\hline CF-Up-9 cm-CF-Down 2 cm & 34.7 & 3.7 & & 42.0 & 3.0 & & \\
\hline Tibial nerve & & & & & & & \\
\hline Ankle- Abd hal & & 3.6 & 6.0 & & 2.8 & & 4.3 \\
\hline Popliteal fossa-Ankle & 56.1 & 1.0 & & 47.9 & 1.7 & & \\
\hline Sensory nerve & $\mathrm{SCV}(\mathrm{m} / \mathrm{s})$ & SNAP $(\mu V)$ & Distal latency (ms) & $\mathrm{SCV}(\mathrm{m} / \mathrm{s})$ & $\operatorname{SNAP}(\mu \mathrm{V})$ & & Distal latency (ms) \\
\hline Median nerve & 38.9 & 2.0 & 4.1 & no response & & & \\
\hline Ulnar nerve & 38.1 & 2.2 & 2.9 & no response & & & \\
\hline Radial nerve & 42.9 & 4.7 & 1.8 & 54.5 & 6.1 & 1.7 & \\
\hline Sural nerve & After biopsy & & & 61.8 & 14 & & 1.7 \\
\hline Posterior tibial nerve & no response & & & no response & & & \\
\hline F wave conduction velocity & $44 \mathrm{~m} / \mathrm{s}($ Ulnar r & nerve); Occurre & ce rate of $5 \%$ & & & & \\
\hline
\end{tabular}

Abbreviations: MCV Motor conduction velocity, CMAP Compound motor action potential, SCV Sensory conduction velocity, SNAP Sensory nerve action potential, $A P B$ Abductor pollicis brevis, $A D M$ Abductor digiti minimi, EDC Extensor digitorum communis, EDB Extensor digitorum brevis, $C F$ Capitulum fibula, Abd hal Abductor hallucis 
motor neuropathy (MADSAM), also known as LewisSumner syndrome [7].

One notable feature in the present case was cranial nerve involvement, which included the facial and hypoglossal nerves. Cranial neuropathy is clinically uncommon in patients with CIDP, although it has been described in several case series or reports, including in cranial nerves II to X, and XII [2, 3, 8-11] (Table 2). A review of the literature revealed a reported incidence of cranial nerve involvement in $5 \%$ to $20 \%$ of patients with CIDP. According to a retrospective study, cranial palsy is frequent in MADSAM (48\%), but less frequent in typical CIDP (11\%) and distal acquired demyelinating symmetric (11\%) [3]. Facial paralysis is the most common involved, followed by bulbar involvement and oculomotor nerve paralysis [3, 8-11]. Typical CIDP patients usually have bilateral cranial nerve involvement, while MADSAM patients frequently have unilateral paralysis [3]. However, reports of hypoglossal neuropathy in CIDP are especially rare $[2,12]$. The present case adds to the few reported cases that indicate the presence of hypoglossal neuropathy in CIDP. Even if tongue fasciculation and atrophy is observed, CIDP should be considered because it is a treatable disorder. Tests should include nerve conduction studies to evaluate for conduction block, demyelination, and sensory nerve involvement, to distinguish this condition from motor neuron syndromes.

Another notable feature in the present case was the presence of an inverted Beevor's sign, which has not been reported previously in CIDP. Beevor's sign, which is an upward movement of the umbilicus with truncal flexion from a supine position, derives its name from Dr. Charles Edward Beevor. It first appeared in his 1898 textbook "Diseases of the Nervous System: A Handbook for Students and Practitioners", and was used to indicate a spinal cord lesion between the levels of T10 and T12 $[4,5,13]$. Several publications have reported this sign in other neurological disorders, but not in spinal cord lesions. It is diagnostic for facioscapulohumeral muscular dystrophy, especially in typical cases, with a specificity of $92.9 \%$ to $100 \%$ and a sensitivity of $53.6 \%$ to $95.0 \%$ [14-16]. Beevor's sign can also be present in the following conditions: GNE myopathy (observed in nearly $90 \%$ of patients) [17], late-onset Pompe disease $[16,18]$, tubular aggregate myopathy [15], myotonic dystrophy type 1 [16], myopathy with TCAP mutations [19], sporadic inclusion body myositis [20, 21], amyotrophic lateral sclerosis [22], and acute disseminated encephalomyelitis associated with demyelinating polyneuropathy [23]. Less frequently, Beevor's sign can also be present in an "inverted" form, namely as the inverted Beevor's sign, where the umbilicus moves downward because of upper rectus abdominis weakness. The inverted Beevor's sign has previously been reported in facioscapulohumeral muscular dystrophy [16, 24] and in Dr. Beevor's myopathic patient [4]. The involvement of nerve roots and extraforaminal segments of nerves in thoracic segments, as well as intercostal nerves bilaterally, has been reported in CIDP [25]. Therefore, the inverted Beevor's sign in our patient may be caused by the involvement of thoracic peripheral nerves.

In conclusion, we described a rare case of CIDP presenting with cranial nerve involvement and inverted Beevor's sign. Cranial nerves may be affected in patients with CIDP. Facial palsy is most frequently present, while hypoglossal nerve involvement is rarely reported. CIDP should be considered in patients who present with cranial nerve involvement. To our knowledge, this is the first report of the inverted Beevor's sign in CIDP. Neurologists should therefore pay attention to the movement of the umbilicus on neck flexion during neurological examinations in neuromuscular disorders.

Table 2 Literature review of cranial nerve involvement in CIDP

\begin{tabular}{|c|c|c|c|c|c|}
\hline Cranial nerve involved & $\begin{array}{l}\text { Shibuya et al } \\
132 \text { cases [3] }\end{array}$ & $\begin{array}{l}\text { Rotta et al } \\
87 \text { cases [8] }\end{array}$ & $\begin{array}{l}\text { Barohn et al } \\
60 \text { cases [9] }\end{array}$ & $\begin{array}{l}\text { McCombe et al } \\
92 \text { cases [10] }\end{array}$ & $\begin{array}{l}\text { Gorson et al } \\
67 \text { cases [11] }\end{array}$ \\
\hline । & 0 & 0 & 0 & 0 & \\
\hline$\|$ & $1(1 \%)$ & 0 & 0 & 0 & \\
\hline $\begin{array}{l}\text { Ophthalmoplegia } \\
\text { (III, IV or VI) }\end{array}$ & $7(5 \%)$ & $3(3 \%)$ & $2(3 \%)$ & $4(4 \%)$ & $2(3 \%)$ \\
\hline V & $4(3 \%)$ & 0 & 0 & 0 & \\
\hline VII & $11(8 \%)$ & $2(2 \%)$ & $8(13 \%)$ & $14(15 \%)$ & $7(10 \%)$ \\
\hline VIII & $2(2 \%)$ & 0 & 0 & 0 & \\
\hline$I X, X$ & $12(9 \%)$ & $1(1 \%)$ & 0 & $6(6 \%)$ & $4(6 \%)$ \\
\hline XII & 0 & 0 & 0 & 0 & \\
\hline Total & $26(20 \%)$ & $4(5 \%)$ & $10(17 \%)$ & $15(16 \%)$ & \\
\hline
\end{tabular}




\section{Abbreviations}

CIDP: Chronic inflammatory demyelinating polyneuropathy; MADSAM: Multifocal acquired demyelinating sensory and motor neuropathy.

\section{Supplementary Information}

The online version contains supplementary material available at https://doi. org/10.1186/s12883-021-02287-5.

Additional file 3: Table 1. Muscle strength evaluation with Medical Research Council scale. Table 2. The nerve ultrasonography of the patient. Figure 1. The magnetic resonance imaging of the lumbosacral plexus of the patient.

\section{Acknowledgements}

The authors extend their appreciation to the patient for his support. Special acknowledgements to Ms. Xin Shi for her help of nerve conduction studies in this patient.

\section{Authors' contributions}

HJZ and YMZ contributed to the drafting, and reporting of the case. LCM, MY $W Z, H L, Z X W$ and $H J H$ contributed to revision of the manuscript. YY contributed to the concept and revision of the manuscript. The authors read and approved the final manuscript. All authors met the authorship criteria from the International Committee of Medical Journal Editors (ICMJE).

\section{Funding}

No funding was received.

\section{Availability of data and materials}

The datasets used and/or analyzed during the current study are available from the corresponding author on reasonable request.

\section{Declarations}

\section{Ethics approval and consent to participate}

Informed consent was obtained from the patient to publish this case, and approval for this study was provided by the Research Ethics Committee of The First Hospital of Peking University.

\section{Consent for publication}

Written informed consent was obtained from the patient for publication of this case report and any accompanying images. A copy of the written consent is available for review by the Editor of this journal.

\section{Competing interests}

The authors declare that they have no competing interests.

\section{Author details}

${ }^{1}$ Neurology Department, Peking University First Hospital, No.8 Xishiku Street, Beijing 100034, China. ${ }^{2}$ Neurology Department, University of Chinese Academy of Sciences Shenzhen Hospital (Guangming), No. 4253 Matian Street, Shenzhen 518000, China.

Received: 28 January 2021 Accepted: 17 June 2021

Published online: 26 June 2021

\section{References}

1. Rodríguez Y, Vatti N, Ramírez-Santana C, et al. Chronic inflammatory demyelinating polyneuropathy as an autoimmune disease. J Autoimmun. 2019:102:8-37.

2. Hemmi S, Kutoku Y, Inoue K, Murakami T, Sunada Y. Tongue fasciculations in chronic inflammatory demyelinating polyradiculoneuropathy. Muscle Nerve. 2008;38(4):1341-3.

3. Shibuya K, Tsuneyama A, Misawa S, Suichi T, Suzuki Y, Kojima Y, Nakamura K, Kano H, Prado M, Kuwabara S. Cranial nerve involvement in typical and atypical chronic inflammatory demyelinating polyneuropathies. Eur J Neurol. 2020;27:2658-61.
4. McCarter SJ, Burkholder DB, Klaas JP, Boes CJ, Charles E. Beevor's lasting contributions to neurology: more than just a sign. Neurology. 2018:90(11):513-7.

5. Althagafi A, Nadi M. Beevor sign. In: StatPearls. Treasure Island: StatPearls Publishing; 2020

6. Joint Task Force of the EFNS and the PNS. European Federation of Neurological Societies/Peripheral Nerve Society Guideline on management of chronic inflammatory demyelinating polyradiculoneuropathy: report of a joint task force of the European Federation of Neurological Societies and the Peripheral Nerve Society--First Revision [published correction appears in J Peripher Nerv Syst. 2010 Dec;15(4):373]. J Peripher Nerv Syst. 2010;15(1):1-9.

7. Doneddu PE, Cocito D, Manganelli F, et al. Atypical CIDP: diagnostic criteria, progression and treatment response. Data from the Italian CIDP database. J Neurol Neurosurg Psychiatry. 2019;90:125.

8. Rotta FT, Sussman AT, Bradley WG, Ram Ayyar D, Sharma KR, Shebert RT. The spectrum of chronic inflfammatory demyelinating polyneuropathy. J Neurol Sci. 2000;173:129-39.

9. Barohn RJ, Kissel JT, Warmolts JR, Mendell JR. Chronic inflammatory demyelinating polyradiculoneuropathy. Clinical characteristics, course, and recommendations for diagnostic criteria. Arch Neurol. 1989;46:878-84.

10. McCombe PA, Pollard JD, McLeod JG. Chronic inflammatory demyelinating polyradiculoneuropathy. A clinical and electrophysiological study of 92 cases. Brain. 1987;110:1617-30.

11. Gorson KC, Allam G, Ropper AH. Chronic inflammatory demyelinating polyneuropathy. Clinical features and response to treatment in 67 consecutive patients with and without a monoclonal gammopathy. Neurology. 1997:48:321-8.

12. Roberto KT, Antonio AKD, Fernandez MLL, Damian LF. Chronic inflammatory demyelinating polyneuropathy with tongue fasciculation: a case report. J Clin Neurosci. 2020;71:297-9.

13. Pearce JM. Beevor's sign. Eur Neurol. 2005;53(4):208-9.

14. Awerbuch Gl, Nigro MA, Wishnow R. Beevor's sign and facioscapulohumeral dystrophy. Arch Neurol. 1990;47(11):1208-9.

15. Shahrizaila N, Wills AJ. Significance of Beevor's sign in facioscapulohumeral dystrophy and other neuromuscular diseases. J Neurol Neurosurg Psychiatry. 2005;76(6):869-70.

16. Eger K, Jordan B, Habermann S, Zierz S. Beevor's sign in facioscapulohumeral muscular dystrophy: an old sign with new implications. J Neurol. 2010;257(3):436-8.

17. Preethish-Kumar V, Pogoryelova O, Polavarapu K, et al. Beevor's sign: a potential clinical marker for GNE myopathy. Eur J Neurol. 2016;23(8):e46-8.

18. Garibaldi M, Diaz-Manera J, Gallardo E, Antonini G. Teaching video Neurolmages: the Beevor sign in late-onset Pompe disease. Neurology. 2016;86:e250-1.

19. de Fuenmayor-Fernández de la Hoz CP, Hernández-Laín A, Olivé M, Fernández-Marmiesse A, Domínguez-González C. Novel mutation in TCAP manifesting with asymmetric calves and early-onset joint retractions. Neuromuscul Disord. 2016;26(11):749-53.

20. Sugie K, Kumazawa A, Ueno S. Sporadic inclusion body myositis presenting with Beevor's sign. Intern Med. 2015;54:2793-4.

21. Milisenda JC, Rico Caballero V, García Al, Tomás X, Grau JM. "Extended" Beevor's sing as a new clinical sign in sporadic inclusion body myositis. Med Clin (Barc). 2017;148(8):e43.

22. Pandian JD, Mathuranath PS. Beevor's sign in amyotrophic lateral sclerosis. Neurol India. 1997:45(4):283-4.

23. Aimoto Y, Moriwaka F, Matsumoto A, Tashiro K, Abe K. A case of acute disseminated encephalomyelitis (ADEM) associated with demyelinating peripheral neuropathy. No To Shinkei. 1996;48(9):857-60.

24. Papadopoulos C, Xirou S, Kararizou E, Papadimas GK. Teaching Video NeuroImages: Inverted Beevor sign in facioscapulohumeral muscular dystrophy. Neurology. 2020;95(19):e2714.

25. Oguz B, Oguz KK, Cila A, Tan E. Diffuse spinal and intercostal nerve involvement in chronic inflammatory demyelinating polyradiculoneuropathy: MRI findings. Eur Radiol. 2003;13(Suppl 6):L230-4.

\section{Publisher's Note}

Springer Nature remains neutral with regard to jurisdictional claims in published maps and institutional affiliations. 